\title{
En defensa de la libertad de expresión
}

\author{
David Marcos ${ }^{\mathrm{I}}$ (100000-0002-9528-3095 \\ Universidad de Granada, Granada, Espanha
}

Resumen: La libertad de expresión en el siglo XXI se ve de nuevo amenazada, no tanto por parte del Estado (que también lo hace) sino más bien por parte de la sociedad civil. Identifico a John Stuart Mill como uno de los que se dio cuenta de este problema. Analizo este problema junto con dos que van unidos a él. El primero es la censura, tanto del Estado como de la sociedad civil. El segundo, la corrección política. Analizo este fenómeno e ilustro el caso concreto de las universidades americanas y de James Flynn. Por último, hago consideraciones sobre la difamación partiendo de las ideas del célebre profesor Walter Block.

Palabras clave: Libertad negativa, libertad positiva, censura, Estado, Mercado, sociedad civil, difamación.

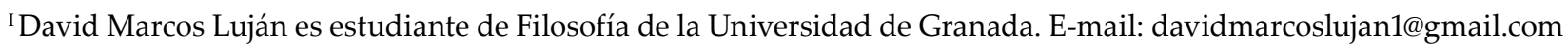




\title{
In defense of freedom of speech
}

\begin{abstract}
Freedom of speech in the 21st century is under threat, not so much by the State (that it is as well) but from civil society. I identify John Stuart Mill as one of those who noticed this issue. I analyze this problem along with two more issues related to this particular problem. The first one is censorship, that comes from the State and from the civil society. The second one is political correctness; I examine this phenomenon and illustrate the concrete case of American universities and the case of James Flynn. Finally, I make some considerations on defamation based on the celebrated professor Walter Block's ideas.
\end{abstract}

Keywords: Negative liberty, positive liberty, censorship, State, Market, civil society, difamation.

\section{Em defesa da liberdade de expressão}

Resumo: No século XXI, a liberdade de expressão está sob ameaça, não tanto por parte do Estado (que também é um problema), mas principalmente por parte da sociedade civil. John Stuart Mill foi um dos pensadores que percebeu esse problema. Analiso esse problema com dois corolários dele. O primeiro é a censura, tanto do Estado, como da sociedade civil. O segundo, através do politicamente correto. Ilustro a situação com os casos das universidades americanas e de James Flynn. Por fim, reflito sobre a difamação à luz das ideias do professor Walter Block.

Palavras-chave: Liberdade negativa, liberdade positiva, censura, Estado, Mercado, sociedade civil, difamação. 


\section{Introducción}

"El hombre es libre simplemente en el momento en que desea serlo".

Voltaire

En este ensayo mi objetivo es defender la libertad de expresión. Para esto, primero me gustaría distinguir la diferencia entre las dos concepciones de libertad, la positiva y la negativa. Esta concepción la concibe Isaiah Berlin en su obra: Dos ideas de libertad (2019)ํ․ La libertad negativa la suelen defender liberales en general, no todos puesto que hay liberales que defienden la libertad positiva, como por ejemplo John Stuart Mill o el propio Berlin, aunque con matices. También la defienden ciertas ramas conservadoras, como la liberal-conservadora (no todas las personas de esta rama la defienden) o la paleo-libertaria ${ }^{2}$ y por supuesto, todo libertario ${ }^{3}$ (que no sea de izquierdas, como ejemplo de libertario de izquierdas pondría a Noam Chomksy) y anarcocapitalista la defiende. De nuevo, me encuentro con otra distinción a la que es menester arrojar luz, la diferencia entre liberal y libertario. Hay una diferencia fundamental entre ambas posturas. El liberal ve al Estado como algo bueno en los aspectos que él (el liberal) cree que serían convenientes, en unas funciones concretas, como lo hace Mises en La acción humana, y el libertario es el que ve al Estado mal por naturaleza ${ }^{4}$.

La libertad negativa es básicamente ausencia de coacción para perseguir los fines que queramos (siempre y cuando respetemos los derechos negativos y libertades de los demás). En palabras de Thomas Hobbes:

Libertad significa, propiamente, ausencia de oposición; por oposición quiero decir impedimentos externos del movimiento (...) Un hombre libre es aquel que, en aquellas cosas que puede hacer en virtud de su propia fuerza e ingenio, no se ve impedido en la realización de lo que tiene voluntad de llevar a cabo. (HOBBES, 2018, p.101)

La libertad positiva, defendida por liberales como John Rawls (y demás que he mencionado anteriormente), por la mayoría de los socialistas (ya sean de izquierda o derecha) y socialdemócratas, es aquella que dice que no hay libertad si no tienes los medios para conseguir tus fines. Por ejemplo, si no tienes dinero para ropa o comida no puedes ser libre ${ }^{5}$. Aquellos

\footnotetext{
${ }^{1}$ Otra distinción de estos dos tipos de libertad se puede ver en el autor Benjamin Constant y su célebre libro Acerca de la libertad de los antiguos comparada a la de los modernos.

${ }^{2}$ El paleo-libertarismo es una rama del libertario desarrollada por teóricos como Lew Rockwell o Murray Rothbard donde se mezclan ideas de la filosofía libertaria con ideas culturales y sociales de la tradición conservadora.

${ }^{3}$ El libertarismo es una filosofía política que defiende las libertades del individuo, los derechos de propiedad y la distribución de los recursos mediante una economía de Mercado sin intervención del Estado en esta.

${ }^{4}$ No por ser libertario se ha de ser automáticamente anarcocapitalista, pensadores como Robert Nozick o Ayn Rand son libertarios y ven al Estado como necesario, eso sí, lo ven como un mal.

${ }^{5} \mathrm{Si}$ se quiere saber más sobre libertad negativa y positiva veo conveniente ver por un lado de Óscar Godoy Arcaya "Republicanismo, liberalismo y democracia" y de Elena García Guitián Liberalismo y republicanismo: el uso político de los conceptos de libertad". En estos dos textos también se explica un tercer concepto de libertad, libertad
} 
que defienden la libertad positiva dicen que la gente tiene derecho a tener cosas, comida, vivienda, salud, etc. Argumentando que no soy libre si no tengo comida, educación... Esto en mi opinión no son derechos puesto que han de ser financiados y están sujetos a precios y a leyes de mercado tales como la de la oferta y la demanda. Los verdaderos derechos, los negativos, no tienen estas características. Estas características las suelen tener los bienes económicos, que es a la categoría a la que la sanidad, la educación y la vivienda (por ejemplo) pertenecen, ya que si no lo fueran, no los demandarían como gratuitos. Los derechos positivos son bienes económicos y servicios, no derechos. El problema de esta concepción de libertad es que esos "derechos" los obtienen a costa de los demás (usualmente mediante el Estado, que es el que cobra impuestos para financiar estos derechos coaccionando a la población) e invadiendo derechos individuales ajenos, entre otros, el de propiedad privada (el de la propiedad privada de mi dinero, fruto de mi trabajo). Todo derecho positivo implica una vulneración de derecho negativo, es decir, un derecho positivo para uno es una obligación para otro. Todo lo que te impida conseguir esos fines implican que no hay libertad. La libertad positiva obliga a las personas a hacer cosas que no quieren y hay personas que ven esto como ético.

Estos dos conceptos de libertad son incompatibles, desde mi punto de vista, la libertad positiva no es más que una libertad falsa, una invasión contra la verdadera libertad, la negativa, $\mathrm{y}$ lo peor de todo es que esto se lo hace en nombre de la libertad.

La libertad de expresión, es un derecho individual ${ }^{6}$ según el cual cualquier individuo tiene total libertad para expresar sus ideas y opiniones sin que se le censure o sancione. La libertad de expresión, entendiéndola como acción (la acción de hablar o decir algo), tiene consecuencias, aquellos que dicen que la libertad de expresión es decir lo que quieras sin represalias (lo uso como sinónimo de consecuencias) pienso que se equivocan, pues toda acción y toda libertad, como argumentó Hayek va irremediablemente unida a la responsabilidad, y yo soy responsable de lo que digo. Por eso, antes de decir algo, hay que pensar bien lo que se dice. Ya decía algo parecido Platón: "los sabios hablan porque tienen algo que decir; los tontos porque tienen que decir algo". La libertad de expresión engloba tres subcategorías dentro de

como no-dominación, de la tradición republicana, aunque ni los propios autores de esta tradición se ponen muy de acuerdo. Entre estos autores están Pettit, Maquiavelo y Pollock. Por último, la obra de Berlin donde establece e introduce esta distinción, Dos ideas de libertad.

${ }^{6}$ Todo derecho es individual, pues como explicó ya Ludwig Von Mises en La acción humana, "solo el individuo piensa, solo el individuo existe, solo el individuo hace, solo el individuo opera" (2018, p.278). Estos autores, entre los que incluyo a Carl Menger (1997) y Friedrich A. Hayek (2017), pertenecen a la Escuela de economía austriaca cuyo método es el individualismo metodológico. Lo que quieren decir estos autores con este método es que solo el individuo tiene existencia ontológica, por tanto, solo el individuo puede tener derechos y libertades, y no los grupos, ya que ontológicamente no existen. Los grupos y las sociedades son abstracciones de los individuos, no tienen materia, no se pueden tocar ni oler, no tienen cara, no pueden coger cosas, y lo más importante, todo grupo depende de los individuos, sin individuos no puede haber grupos, por eso, entre otras cosas (como evitar el despotismo), el individuo siempre ha de ir por delante del grupo y tener más importancia que este. Sobre esto se puede ver el libro Comunidades imaginadas de Benedict Anderson (2006). Para conocer más sobre el individualismo metodológico, se puede ver el libro de Carl Menger, El método de las ciencias sociales o el capítulo dos de La Acción humana de Mises, The Principle of Methodological Individualism. 
sí, las cosas que me gustan y con las que estoy de acuerdo, las cosas que no me gustan y con las que no estoy de acuerdo y por último las cosas que me dan igual7.

Dicha esta aproximación breve al concepto de libertad y libertad de expresión, haré un acercamiento al pensamiento sobre libertad de expresión en John Stuart Mill. También comentaré uno que otro caso concreto de censura de libertad de expresión en la actualidad, considerando que la censura no viene ya desde el Estado como ha sido históricamente sino que viene de la sociedad civil. Analizaré el fenómeno de la corrección política y por último haré una defensa del derecho a ofender y la difamación, que realmente estarían, ambos, dentro de la libertad de expresión, sólo que como subcategorías. Pienso que el debate actual está entre aquellos pro-censura que prefieren sacrificar libertad por seguridad y aquellos anti-censura que no quieren dar su libertad. Yo me posiciono con los segundos. Sobre difamación, el autor principal al que trataré será Walter Block.

Pero si la difamación no es el límite de la libertad de expresión, entonces ¿cuál es? Esta será la última cuestión que trataré.

\section{John Stuart Mill y la libertad de expresión}

"Todo aquello que sofoca la
individualidad, sea cual sea
el nombre que se le dé,
es despotismo".
John Stuart Mill

\subsection{Introducción a Stuart Mill}

John Stuart Mill es un escritor y filósofo liberal. Liberalismos, al igual que socialismos, hay de muchos tipos y diferentes ramas. Yo diría que Mill es un liberal heterodoxo ya que se aleja mucho de los postulados en cuanto a gobierno limitado que planteó Locke y además defiende la libertad desde una perspectiva diferente a la mayoría de los liberales. Él la defiende desde el utilitarismo, no desde el deontologismo, como hacen los demás teóricos liberales. Sus obras, entre ellas la principal, Sobre la libertad, admite mucha variedad de lectura, es decir, a este autor se le puede interpretar de formas diferentes. También forma parte de la tradición ética del utilitarismo ${ }^{8}$, aunque aquí también es heterodoxo pues no sigue del todo al utilitarismo

\footnotetext{
${ }^{7}$ También creo que es menester decir que la libertad de expresión es un derecho de propiedad, del uso que yo crea conveniente de mi cuerpo a decir x o decir z y por eso entra en contraposición con los demás derechos de propiedad. Si alguien no quiere que yo diga x cosas en su propiedad mi derecho a la libertad de expresión aquí queda "limitado" al tener que seguir las reglas que otro dice que he de seguir en su propiedad, como por ejemplo su casa. Si fuera mi casa, es decir, mi propiedad, sí estaría legitimado a decir lo que yo quisiera porque esa casa es mía. Véase a George Reisman (2011), un defensor de la libertad de expresión como derecho de propiedad en este artículo titulado Free Speech and occupy Wall Street. Acceso en: https://mises.org/library/ free-speech-and-occupy-wall-street. 21/12/2011.

${ }^{8}$ Bajo mi punto de vista es esta la principal razón por las Mill (2010; 2011; 2014; 2019) abraza las nociones de libertad y derecho positivo, él fue criado en esta tradición. El liberalismo más verdadero es deontológico, aunque
} 
clásico de Jeremy Bentham. En algunos de los temas que trata este autor se le conoce por ser muy ambiguo, uno de estos temas sería la economía donde no se sabe bien si es liberal con toques socialdemócratas o socialdemócrata con toques liberales. Lo mismo le pasa con la educación, dice que sea pública pero no dice cuánta debe que haber ni hasta qué edad, es decir, no concluye. En el pensamiento de este autor también se ve algo de socialismo. Mill conocía el socialismo marxista pero no siguió esta variante, se decantó más por un socialismo de corte francés, como el de Saint-Simon (1816-1818; 1823-1824). No se opone al socialismo como otros liberales hacen pero no lo ve posible en su contexto. Mill dice con el socialismo lo mismo que Hume dice con el anarquismo, algo así como "es un estado de perfección del que acertadamente se considera incapaz a la naturaleza humana" (HUME, 2011, p.102). Es por ello, que liberales de otras ramas, como por ejemplo el de corte austriaca, lo llaman socialista y hacen una dura crítica contra él. Ludwig Von Mises (2011, p.261-262) llega a decir en Liberalismo:

"John Stuart Mill es ya un epígono del liberalismo clásico. En su vejez, influido por su mujer, cedió a toda una serie de compromisos, hasta deslizarse lentamente hacia el socialismo. Él es el responsable de la desenvuelta mezcolanza de ideas liberales y socialistas que llevó a la decadencia del liberalismo inglés e hizo vacilar el bienestar de la población inglesa (...). En efecto, Mill es el mayor defensor del socialismo; todos los argumentos posibles a favor del socialismo fueron cuidadosamente elaborados por él. Junto a Mill todos los demás autores socialistas - Marx, Engels y Lassalle incluidos - casi desaparecen".

En cuanto a quién debería gobernar, Mill (2001) expone en otra de sus obras, El gobierno representativo, que ha de ser una especie de cúpula intelectual. En esta obra se puede ver su carácter más elitista, que recuerda un poco a Platón (2011) o a Bacon (2006) pues Mill propone que gobiernen aquellos hombres que sean más sabios, ilustres e ilustrados. Más del filósofo de la atalaya que del filósofo de a pie.

\subsection{Mill y la libertad de expresión}

La tesis principal de Mill aquí es que todos los temas han de ser llevados a debate, a la libre discusión y al libre examen. No se mete tanto en temas de censura estatal y tiranía del Estado. Históricamente, el Estado había sido el principal órgano censor de la sociedad civil. Stuart Mill ve ahora como principal censor no tanto al Estado sino sobre todo a la propia sociedad civil. Es decir, su principal preocupación es la opresión de la tiranía social, la opinión pública, las sanciones religiosas, la opresión de las sociedades y comunidades... Ve que la (o) presión social pueda ser el principal problema en cuanto a la libertad de expresión pues esta puede cohibir a las personas de expresarse tal como piensan y son.

Creo que es importante reflexionar sobre el concepto de opresión y hacer unas cuantas consideraciones. Yo entiendo opresión como que se me impida hacer algo, es decir, que sea vea

se puede matizar mucho aquí y hay un debate largo. ¿Hasta qué punto hay que ser deontologista? No creo que haya que llegar al nivel absoluto, extremo y radical de Kant ya que puede ser incluso contraproducente, en este debate me posiciono más con Benjamin Constant y abogo por un deontologismo racional (por más que le pese a Kant (2012; 2013). 
vulnerada mi libertad negativa (mi capacidad de actuar siempre que no invada la libertad de los demás). Esto actualmente no es así, en 2019 se ha llegado a entender por opresión que no llames a alguien como él te diga, llamar a alguien él en vez de ella puede ser problemático en ciertos contextos. Véase el ejemplo de Canadá o en Argentina con las hate crime laws. No creo que no llamarme por mi nombre sea opresión, pues esto no me impide actuar. Opresión desde mi punto de vista es la mayoría de las veces violencia, pues este sí es un modo de que se te impida actual y no una presión cultural o social. Que no me quieran hablar o juntarse conmigo por cualquier razón no es opresión, yo no puedo obligar a nadie a que hable conmigo o se junte conmigo. A lo que apunta Mill es a que este tipo de cosas como la presión social cohíba a la gente de decir sus opiniones (entre otras cosas), - lo que viene a ser autocensura- por miedo a que, para dejarlo claro con una metáfora, "se rían luego de nosotros en el bar". Puede ser un problema o no, lo que yo creo que está claro es que no es opresión pues una presión social no me impide hablar o actuar. Cuando me impida hablar o actuar si será opresión porque seguramente habrá coacción de por medio. Pero que la sociedad civil sea "mono-pensadora" e intolerante sí es un problema y en eso Mill tiene toda la razón", pues lo que harán será tratar de silenciar y estar ahí para impedir que hables y en el caso de que hables y digas algo con lo que la masa no está de acuerdo, prepárate para sufrir una lluvia de acusaciones (como mínimo). Esto se ve bien en la sociedad actual, donde se usa la palabra "fascista" para acusar a los que no piensan como el mainstream y se tiende al ad hominem en vez de intentar rebatir el argumento racionalmente. El ejemplo claro de esto se puede ver actualmente en los campus norteamericanos cuando hablan personas como Jordan Peterson (2016) o Ben Shapiro (2016). ${ }^{10}$ Analizaré la situación de las universidades americanas más adelante. Creo que Mill (2019) sí ha identificado bien el problema, el caso es que yo no lo llamaría opresión sino intolerancia, simplismo o infantilismo. El censor ya no es el Estado como en 1984 de Orwell, la situación es más triste, el censor ahora no es otro que la sociedad civil. Mill dice lo siguiente:

"Protection, therefore, against the tyranny of the magistrate is not enough. There needs protection also against the tyranny of the prevailing opinion and feeling" (MILL, 2019, p. 7). ${ }^{11}$

Por estas cosas, Mill es de los que piensan que hay un derecho a hablar de lo que queramos, sin tapujos. Para su tesis del debatir todo y del libre examen, Mill da tres principales argumentos sobre por qué debería ser así y por qué debería haber libertad de expresión. Antes de nombrar los tres argumentos también explica Mill en Sobre la libertad que cree que ese debate de todo sería la mejor forma de llegar a la verdad, debatiendo nuestras ideas con

\footnotetext{
${ }^{9}$ También incide en esto Isaiah Berlin (2014), este erudito pensaba que una sociedad mono-pensante tenderá más fácilmente y más rápidamente hacia el totalitarismo. Tocqueville apunta a esto también en su libro $L a$ democracia en América (2018), caracterizando esto como la tiranía de la igualdad.

${ }^{10}$ Se puede apreciar esto en las referencias de los vídeo en el apartado de la bibliografía. Por ejemplo, véase el siguiente vídeo de Youtube: https://www.youtube.com/watch?v=O-nvNAcvUPE. Acceso en: 1 ene 2014.

${ }^{11}$ Jonathan Haidt y Richard V. Reeves, John Stuart Mill's ideas on free speech ilustrated. (2018-2019, p. 2). Disponible en: https://heterodoxacademy.org/mill/. Acceso en: 1 ene 2019. En este paper se desarrollan mucho más los tres argumentos que he introducido y también se desarrollan más en el capítulo 2 de On Liberty de Stuart Mill (2019).
} 
las de nuestros contrarios, en vez de encerrarse cada uno en su parte de la ciudad y estar eternamente peleados, como las dos familias antagónicas de Romeo y Julieta.

Estos argumentos los desarrolla Mill en su obra Sobre la libertad (2019), pero aquí los nombraré de forma resumida. El primero argumento que da Mill es que por muy rara o extraña sea la idea de la otra persona, podría resultar que esta tuviera razón. El segundo argumento es que aunque tu opinión e ideas estén mayoritariamente correctas y las comparta la mayoría, debatiéndolas con otra persona podrías mejorar aún más como resultado de haber sido estas cuestionadas. El tercero es que incluso la idea más chocante puede tener una porción o una pizca de verdad y podrías acoplar ésta a tu teoría, es decir, combinar ambas ideas. Estas en resumidas cuentas son las razones que Mill da para explicar que merece la pena debatir con los demás y es la mejor forma de acercarse a la verdad.

En conclusión creo que Mill (2019) ha visto bien el problema y es pertinente su análisis ahora más que nunca, en tiempos donde la intolerancia, no del Estado sino de la sociedad civil, que es mucho peor, ha surgido.

\title{
2. Libertad de expresión y censura desde el Estado y la sociedad civil
}

\author{
"To suppress free speech is a \\ double wrong. It violates the \\ rights of the hearer as well as \\ those of the speaker". \\ Frederick Douglass
}

\subsection{Censura desde el Estado}

El enemigo principal de la libertad de expresión es la censura, así que es necesario explicar cómo esta se ha dado a lo largo de la Historia y cómo se da actualmente. La censura ${ }^{12}$ en el siglo XXI ya ha dejado de venir del Estado como ha sido históricamente, sobre todo en aquellos períodos de la Historia de pensamiento único, estos períodos suelen corresponder a dictaduras. Aunque es cierto que desde el Estado todavía hay penas por decir lo que uno piensa, sea la barbaridad que sea. En el Estado español está el de injurias, ultraje y calumnias a la corona, donde por insultar $\mathrm{u}$ ofender al rey (y en realidad no sólo al rey), se te puede poner una multa y pena de cárcel (BOE, 1995, artículos del código penal del 205 al 216) ${ }^{13}$. Voltaire ya lo dejó muy claro, se dice que él dijo algo así como "si quieres saber quién manda, mira a quien no puedes criticar". En España, el rey mandar no manda nada, esto que dice Voltaire es cierto en su época donde antes de la Rev. Francesa había una monarquía absoluta y el rey

\footnotetext{
${ }^{12}$ Se define censura como aquel acto que impide a los individuos expresar aquello que ellos vean conveniente o que por decir lo que ellos piensen o crean se imponga una sanción estatal como por ejemplo una multa o pena mayor. La presión social no es censura.

${ }^{13}$ Artículos del 205 al 216. Disponible en: file:///C:/Users/Usuario/Downloads/BOE-038_Codigo_Penal_y_ legislacion_complementaria.pdf. Acceso en: 1 ene 2019.
} 
ahí sí mandaba. Ahora en vez de tener el poder absoluto el rey, lo tiene el pueblo, de ahí viene la palabra democracia, que etimológicamente significa poder absoluto (kratos) del pueblo (demos). Pero no es menester aquí comparar monarquía absoluta y democracia (HOPPE, 2013) ${ }^{14}$. Para saber quién manda, mire hacia dónde va el dinero y la ganancia, es decir, hacia el aparato coercitivo llamado Estado. El rey actualmente en España no manda pero tampoco se le puede insultar, esto no lo veo bien ya que me impide un libre uso de mi cuerpo, trataré esto más fondo en el capítulo sobre difamación ${ }^{15}$. Esta es la única medida por parte del Estado en la que veo 'censura'.

El Estado, por su naturaleza y carácter monopolístico siempre ha censurado, es peligroso que la gente sepa cosas que el Estado no ve bien que sepan, como los innumerables fallos que tiene este o lo inmoral que es, por poner dos ejemplos. Por eso, desde la Rev. Francesa, que fue cuando se creó el Estado-Nación o el Estado 'liberal' moderno este ha tenido reiterados actos censores. Usualmente se prohibían, censuraban y quemaban libros y las personas que escribían estas cosas eran perseguidas por ser 'peligrosas' (caza de brujas), en lenguaje del Estado, un peligro nacional que ataca a la estabilidad de la nación. No sólo había censura en la Rev. Francesa, también hubo en la URSS y en los demás fascismos (Italia, Franquismo, Nazismo), es decir, en todo el pensamiento igualitarista que intenta homogeneizar a la sociedad, puesto que todo aquello que no sea igual a lo que el Estado dice es automáticamente considerado como peligroso. Aun así, ha habido resistencia contra el poder del Estado y hay algo contra lo que el Estado nunca ha podido por más que ha intentado, esto es el Mercado ${ }^{16}$. El Mercado al final siempre termina haciéndose hueco de una forma u otra, si se le deja en paz aparece lo que F.A. Hayek (2017) llamó orden espontáneo. El orden espontáneo es el surgimiento espontáneo ${ }^{17}$ de un orden en el aparente caos que provoca la libertad, este orden se debe a la autoorganización de los individuos cuando siguen aquellos fines que ven convenientes. Cuando no se deja al Mercado (a las personas) actuar, aun así este actúa, aunque de forma "ilegal" para los ojos del Estado, esto es lo que se conoce como Mercado Negro ${ }^{18}$. Al final al Mercado le pasa como a la verdad, si la echas por la puerta te entra por la ventana y si la echas por la ventana te entra por la chimenea. El Mercado, como la verdad, siempre gana y ninguna censura podrá contra

\footnotetext{
${ }^{14}$ Esto ya lo ha hecho el filósofo Hans-Hermann Hoppe (2013) en su obra Democracia, el Dios que fracasó. Allá cada uno con lo que prefiera ser devorado, si por las garras de un león o por una manada de mil ratas. Voltaire está en el equipo uno.

${ }^{15}$ El último ejemplo de esto en España se puede ver con las canciones del rapero Valtonyc, donde alienta a matar policías y a la corona real por ser tiránicas, ilegítimas y demás razones. Yo no estoy de acuerdo con lo que él dice en absoluto pero sí que defiendo su derecho a decirlo, aunque solo suelte burradas que no hay realmente por dónde coger ni tienen fundamentación, tiene derecho a hablar y decir lo que quiera. Pensar como Hitler o Stalin no es delito, actuar como ellos sí.

${ }^{16}$ Se define Mercado como relaciones libres y voluntarias entre los individuos, estén sujetas a precios o no, la caridad y la solidaridad también son Mercado, pues no hay coacción (invasiones a las libertades negativas), de ningún tipo, de por medio. Mercado realmente, es la sociedad civil.

${ }^{17}$ Algo espontáneo es algo que aparece sin un previo plan o pensamiento pensado o figurado antes.

${ }^{18}$ Hay teorías políticas (simplificando enormemente) que creen que el Mercado Negro es el mejor modo pacífico para alcanzar una sociedad anarcocapitalista. Este es el caso del Agorismo, se puede ver en la obra de pensadores como Samuel Konkin, Manifiesto neolibertario (2011).
} 
este y en el siglo XXI aún menos con Internet. Se suelen censurar en general pensamientos que van contra lo hegemónico ya sea en arte, literatura, cine, expresiones de la lengua, prácticas personales...

\subsection{Censura desde la sociedad civil}

Ahora, en los tiempos en los que vivimos, ha ocurrido un nuevo fenómeno, la censura viene ahora por manos de la sociedad civil, de la gente, por parte de empresas (como en el caso de James R. Flynn que analizaré más adelante). Las empresas, al ser un espacio privado están legitimadas a censurar dentro de ese espacio privado siempre y cuando no haya ya un contrato establecido de por medio. Sin embargo, que estén legitimadas a hacerlo no significa que eso sea positivo. También la censura viene de parte de individuos, lobbys, grupos de pensamiento...

En España estos intentos de censura se han dado últimamente bastante, lo último que he visto ha sido el intento de boicot contra el partido político Vox cuando su presidente, Santiago Abascal ha sido invitado al programa El Hormiguero para que se le hiciera una entrevista. Cierto sector de la izquierda ha visto esto como una maniobra para "normalizar el fascismo y la ultraderecha". Uno de estos que se han posicionado en contra de esta acción del Hormiguero ha sido el grupo de música Los Chikos del Maíz. Es importante este fenómeno pues con otros políticos a los que yo considero extrema izquierda como Alberto Garzón, Pablo Iglesias e Iñigo Errejón esto no pasa y nadie ha dicho nada ${ }^{19}$. Si son de izquierdas no pasa nada pues el socialismo es bonito, bueno y angelical y todo aquello que critique mínimamente la socialdemocracia tripartita actual es neoliberal, peligroso y cuasi-demoníaco. Estos grupos se quejan de que Abascal vaya a una TV privada a hablar de sus cosas pero no de que Otegui vaya a la TV pública. Este último señor ha formado parte de la organización criminal ETA, la cual ha matado, secuestrado gente y hecho atentados terroristas con bombas. Lo llevan a la TV pública donde gente cuyos familiares han podido ser víctima de esta banda criminal está pagando esa misma TV adonde lo llevan y retransmiten.

Esto está muy relacionado con lo que viene a ser la corrección política, entendida como un lenguaje, unas políticas o medidas hechas para no ofender a la gente o no poner en desventaja a determinados grupos de la sociedad. Este fenómeno lo analizaré más adelante también. Pero cabe hacer aquí una breve introducción.

La corrección política, el no poder hablar más allá del mainstream de ciertos temas como la inmigración, las identidades de género, la interseccionalidad, el cambio climático, el islam... se ha convertido en una tiranía, 'la tiranía de lo políticamente correcto'. Si criticas algunos de estos temas más allá de la visión izquierdista eres un opresor y no tienes realmente derecho a hablar pues eres unas de las clases privilegiadas del mundo, hombre heterosexual, blanco, de clase media, capitalista, occidental... Eres un opresor y tú has de callar y dejar que los 'oprimides' hablen y hacer lo que otra gente, más deconstruida que tú, te ordenan.

\footnotetext{
${ }^{19}$ Los considero de extrema izquierda porque han venerado más de una vez a dictadores de extrema izquierda, como Fidel Castro, Maduro, Evo Morales, Lenin y defienden políticas que aplicaban estos.
} 
Ya avisaba Tocqueville sobre la tiranía de la igualdad, una de las formas de esta 'dictadura' sería la corrección política. Quiero resaltar que lo políticamente correcto actualmente viene de mano de la izquierda, ya lo dijo muy claro Frank H. Knight sobre la tesis de Hayek en Camino de Servidumbre:

Este trabajo consiste en mostrar por medio de un razonamiento general e histórico, y esto último sobre todo con referencia al curso de los acontecimientos en Alemania, dos cosas: primero, que cualquier política que se diga socialista, o de economía planificada, conduce inevitablemente al totalitarismo y a la dictadura; $y$, segundo, que un orden social así acaba cayendo inevitablemente bajo el control de «los peores» individuos. (KNIGHT, 2010, s/p.)

Serán los sectores más liberales, libertarios y derecha no estatista la que deberá combatir contra este fenómeno, liderando y dando la cara sin miedo en la batalla de las ideas.

\title{
3. Corrección política
}

\author{
"La corrección politica es \\ tiranía con modales". \\ Charlton Heston
}

\subsection{Corrección política y las universidades americanas}

Diversos autores han tratado el tema de la corrección política en las universidades. En este capítulo me quiero centrar en lo que dice Camille Paglia (2016) al respecto ${ }^{20}$. Paglia culpa a los profesores de universidad de no admitir que lo políticamente correcto es un problema social y académico con una creciente burocracia favorecida por regulaciones estatales. Lo políticamente correcto es una característica de las revoluciones modernas, empezó en la Rev. Francesa, la cual se inspiró en la americana. En las revoluciones los rebeldes destrozan las instituciones de un sitio y purgan a la clase dominante. En la Rev. Francesa es lo que se conoce como aristocidio. Después de esto, los rebeldes empiezan a purgarse entre ellos, jacobinos contra girondinos tras guillotinar al rey, y bolcheviques contra mencheviques en la Rev. Rusa después de asesinar a la familia zarista. A partir de ahí, los principios revolucionarios se convierten en eslóganes, se crea un partido político, se institucionaliza el partido al llegar al poder, empieza a dar servicios... ${ }^{21}$. De una parte de la sociedad civil se pasa al Estado y del Estado se pasa al resto de la sociedad civil. En EE. UU. antes de los años 1960 la hegemonía ideológica la tenía

${ }^{20}$ Algunas de las cosas que explico a continuación las trata Camille Paglia en una conferencia, en el Smart Set Forum, Free Speech on the College Campus, en el 21 de abril en la Drexel University. Una versión retocada del discurso accesible en: https://ctxt.es/es/20160720/Culturas/7333/libertad-de-expresi\%C3\%B3n-universidadcampus.htm. .20/07/2016.

${ }^{21}$ Esto está muy relacionado con la Teoría Predatoria de Estado, también conocida como Teoría libertaria del Estado, es decir, el cómo surgen los Estados. Diversos autores han tratado esto, como el antropólogo Robert Carneiro (1970), el filósofo David Hume (2006), y distintos sociólogos como Franz Oppenheimer (2014), Alexander Rustow (2014), Charles Tilly (s/f) o Michael Mann (1997). 
el conservadurismo ${ }^{22}$. Se solía censurar todo aquello que oliera a sexo, erotismo y porno, era una sociedad bastante puritana, por así decir. En los años 1960, se da una revolución cultural entre otras cosas dice Paglia por la música poco ortodoxa como la de Elvis Presley con sus raras coreografías y otros grupos como los Rolling Stones o The Doors. Los universitarios, en especial las mujeres, empezaron a liberar su lenguaje y decían palabrotas y utilizaban un lenguaje más soez. Perdieron la vergüenza contra la ortodoxia predominante. La izquierda a partir de ahí ha ido ganando con el tiempo hegemonía en las universidades y posee ella ahora la ortodoxia. La diferencia es que ahora es una ortodoxia aún más tiránica ya que apoyan la supresión de ideas que van en contra de esta. Es lo que era el conservadurismo de los años 1960, sólo que peor.

La deriva izquierdista de la revolución de los años 60 llegó a las universidades donde se crearon rápidamente programas y departamentos altamente politizados. Siguiendo a Paglia (2016), cada una de las áreas acabó gobernada como un campo autónomo y con un discurso ideológico intocable en el momento de su creación. Pienso que deberían haberse mezclado las disciplinas y los departamentos junto con gente con diferentes opiniones, es lo que hace realmente rica a una Universidad, el disenso. Cualquier opinión que vaya en contra de las enseñanzas impartidas, entre ellas la de las Identity Politics, se ve como en la Edad Media se veía a aquel que no creía en Dios o en el siglo XXI a aquel que no cree en la existencia ontológica del Estado, un hereje diciendo una herejía. Además son tan poco objetivos estos docentes que nunca explican la posición contraria a lo que están contando, esto tiene un nombre, adoctrinamiento.

Al estar los departamentos sólo compuestos de pensamiento único, tratan las opiniones disidentes como una ofensa que ha de ser suprimida (PAGLIA, 2016). Según Paglia, la ideología de estos departamentos está basada en la victimización (uno de los rasgos del feminismo radical y de género y de las Identity Politics) y es el resultado de la institucionalización de las ideas revolucionarias de los años 1960 y 1970.

También es cierto que la enseñanza es difícil hacerla objetiva ya que en el momento en que el profesor selecciona unos contenidos u otros está siendo subjetivo y partidista. El profesor, si se posiciona políticamente tiene que enseñar las ideas que van en contra de aquello que predica y dejar a los estudiantes que mantengan las opiniones que quieran sobre cualquier tema. Más de una vez se ha expulsado a un alumno en Gran Bretaña por ejemplo por decir que sólo hay dos géneros.

Dice Paglia, comparando la actualidad con la ortodoxia de los años 1960, que al menos estos últimos buscaban la verdad rigurosamente y no tenían como objetivo adoctrinar.

La universidad según esta pensadora debería promover debates sobre los grandes temas de la actualidad donde se vean ideas diferentes. De nada sirve poner a debatir a dos personas que están de acuerdo. La experiencia universitaria debería estar basada en la confrontación de ideas, los valores de la universidad deberían ser la enseñanza libre y la libertad de expresión, no el adoctrinamiento (PAGLIA, 2016).

\footnotetext{
${ }^{22}$ Conservadurismo estatista, lo que lo convierte en socialismo de derechas.
} 


\subsubsection{El caso de James Flynn}

James R. Flynn es un académico de la universidad de Otago en Nueva Zelanda e iba a publicar un libro titulado In Defense of Free Speech: the University as a censor por la editorial Emerald Press ${ }^{23}$. Al final, la editorial pese a haber dicho que sí anteriormente, ha decidido no publicárselo porque "el trabajo aborda temas delicados de raza, religión y género". También añaden que el trabajo podría incitar al odio racial y religioso, aunque el autor no tenga intención de ello. Como había dicho en el apartado anterior, todo aquello que critique al statu quo es peligroso y ha de ser eliminado, porque puede herir sensibilidades o refutar las teorías vigentes, y bueno, nadie al parecer querría eso. Flynn ve lo mismo que ve Paglia, la izquierda ahora es lo mismo que en lo que era la derecha en la era McCarthy durante la época de la guerra de Vietnam. Aunque para Flynn no solo tienen la culpa los profesores sino también los activistas estudiantiles, que se han vuelto bastante intolerantes.

Pienso que la Universidad ha de ser el templo del pensamiento crítico, no el templo de repetición de dogmas. Se ve actualmente el fenómeno de la restricción de la libertad de expresión por miedo a ofender. Flynn ve que las universidades censuran su enseñanza, el activismo tiende a censurar el lado opuesto y los académicos se censuran a sí mismos. Este no es más que el problema que avistó Stuart Mill en el siglo XIX.

Concluye Flynn que las universidades ya no son lugares para el pensamiento crítico ni crean humanos autónomos que piensen por sí mismos y sean buenos ciudadanos a pesar de que digan que su objetivo es justamente este (FLYNN, 2019) ${ }^{24}$.

\subsection{Sobre el fenómeno de la corrección política}

Detrás de este fenómeno con ánimos de censura, se pueden ver cinco principales cosas, idiotez, buenismo, sesgo, crueldad y autoritarismo. La corrección política se genera cuando las cinco se mezclan en una. Aquellos que se dicen más tolerantes, más apegados al progreso, son justamente lo contrario. Se puede ver por ejemplo en el último congreso de la universidad de Edimburgo sobre racismo, donde a los blancos no se les permite hablar en el turno de preguntas (CRAMB, 2019).

Como decía, la corrección política del siglo XXI viene de mano de ideas de izquierdas con una gran influencia marxista. Este fenómeno se lleva muy bien con ciertos tipos de pensamiento, como por ejemplo el relativismo cultural. Este pensamiento dice que no hay cultura mejor que otra y que todas son iguales. Me pregunto yo, como ya hizo Thomas Sowell (2013), cómo siendo todas tan iguales tienen resultados tan diferentes. Critican bastante a todo lo occidental porque creen que no es tan buena esta civilización como se cree. Aquí es donde meten tesis

\footnotetext{
${ }^{23}$ Esta es una editorial británica, el fenómeno de la corrección política se da con mayor fuerza en EE. UU., aunque en Europa también existe.

${ }^{24}$ Estas opiniones de Flynn se pueden ver en su artículo para Quillete que escribió cuando le censuraron el libro. Disponible en: https:/quillette.com/2019/09/24/my-book-defending-free-speech-has-been-banned/. Acceso en: 24 sep 2019.
} 
marxistas, como que la civilización occidental es explotadora, colonialista e imperialista. Yo estoy más con la tesis que Steven Pinker (2018) mantiene en defensa de la Ilustración, donde demuestra con datos que la civilización occidental es objetivamente mejor dado que las culturas se pueden comparar ${ }^{25}$. Axel Kaiser (2020) ha visto el problema muy bien y siguiendo a este se crean una serie de temas que no se pueden tocar, tabúes, dogmas inamovibles y absolutos que aquellos que los defienden los ven como válidos todo tiempo y en su lugar todo disidente es peligroso. Esto no es otra cosa que cargarse a la filosofía entera y su principal característica, la actitud y pensamiento crítico y la búsqueda de la verdad. El no poder ir contra la autoridad, el pensamiento crítico típico del filósofo es el que lo cuestiona todo. Solía decir algo con este espíritu un profesor mío que deja la cuestión cristalina, Santiago Navajas, "el buen liberal es aquel que molesta a todo el mundo, incluido a los propios liberales".

Otra de los pensamientos a los que está unido el fenómeno es el de que el género es una construcción social y que no hay diferencias entre hombres y mujeres más allá de la cultura. Un planteamiento en contra de la biología, psico-biología, neurología... Esta serie de ideas, propugnadas por pensadoras feministas como Simone de Beauvoir o Judith Butler, algunos las han calificado como ideología de género.

Otro de los temas es el de la inmigración, si te posicionas en contra de la inmigración ilegal o estás a favor de fronteras cerradas automáticamente eres calificado como fascista, xenófobo, racista, machista o nazi sino lo son todas a la vez.

La corrección política, como dice Axel Kaiser (2020), es la nueva inquisición. No se dan cuenta, que descalificando al disidente así no hacen más que actuar como aquellos fascistas a los que tanto odian pero que tanto se parecen y cometer infinitas falacias ad hominem, el debate racional ha sido dejado de lado y se ha optado por un infantilismo y un sentimentalismo brutal.

Está estrechamente relacionado con la cultura del victimismo, ya no es la víctima el obrero explotado por el empresario burgués sino una serie de minorías oprimidas por el sistema neoliberal, (hetero) patriarcal, occidental... Se ve todo desde la lupa del conflicto (que es una tesis marxista), pero la lucha ya no es de una clase social contra otra tipo burguesía-proletariado sino el grupo (homogeneizado) de los hombres heteros, blancos y demás adjetivos contra las minorías oprimidas (también homogeneizadas) por este. Digo que están homogeneizadas porque aquel de la minoría que disienta de lo que las figuras líderes de estos dicen están alienados por el sistema y no ven la realidad bien, exactamente lo mismo que pasaba en el marxismo clásico con el obrero que disentía. Esto es lo que se ha llamado marxismo cultural. En esta cultura del victimismo se premia a aquellos que son considerado víctimas y se castiga socialmente a aquellos considerados agresores. El incentivo pues está en ser víctima, cuanto más víctima y más oprimido hayas sido más premiado eres, en vez de estar este en la responsabilidad individual como propone el liberalismo. La sociedad ahora te recompensa por ser víctima en

\footnotetext{
${ }^{25}$ Pinker (2019) utiliza criterios como la mejor calidad de vida de las personas, el nivel de libertad, calidad medioambiental.
} 
vez de alentar los obstáculos que a uno se le ponen delante esforzándose y trabajando duro. Si se premia a la víctima se crea el incentivo para ser víctima ${ }^{26}$.

Esto no hace más, como vio Mill, que la gente se cohíba y no exprese sus opiniones por miedo. Para mí este es un grave error, y no hay peor censura que la autocensura. La solución tal como yo lo veo, es el coraje, el dar la batalla de las ideas, el combatir las ideologías. En no ser un cobarde, en dar la cara sin temor o como diría Axel Kaiser, 'en no ser oveja', en no dejarse llevar por lo que qué dirá el resto del rebaño. Dar la batalla siempre, el liberal-libertario tiene que ser un pesado, ser constante, machacón, insistente, es más, tiene que ser el más pesado y dar la vara con sus ideas a todo el mundo con el mayor entusiasmo y la mayor alegría.

\title{
4. En defensa de la difamación
}

\author{
"Si la libertad significa algo, \\ será, sobre todo, el derecho \\ a decirle a la gente aquello \\ que no quiere oir". \\ George Orwell
}

El campeón designado para explicar esta postura es el profesor Walter Block que fue quien la puso en el terreno de juego ${ }^{27}$. Block explica que han de ser despenalizadas algunas posturas que tiene el gobierno respecto a ciertas actividades que este ve subjetivamente mal cuando en realidad no hacen daño a nadie y añado yo, podrían incluso beneficiar. Esto lo llama él "delito sin víctima” siguiendo la tradición del legendario anarquista individualista Lysandeer Spooner (2012, s/p). Entre estos delitos sin víctima estaría la drogadicción o la prostitución. Estos delitos son acciones que no dañan a individuos concretos sino que sólo incumplen una ley estatal, por tanto estas acciones son sometidas a censura y prohibición.

Entiendo yo como delito que el individuo Juan dañe a Jaime o a una propiedad de Jaime, como por ejemplo su casa. Si Juan le quema la bicicleta a Jaime (siempre que Jaime la haya obtenido legítimamente, es decir, sin robo o violencia) Juan tendrá que pagarle la reparación de la bicicleta a Jaime. La bicicleta es una propiedad tangible, es decir, se puede tocar, lamer, ver... Aquí viene ahora el problema, ¿Qué pasaría entonces con aquello que es intangible, que no se puede tocar ni ver? ¿Es la reputación y el honor un derecho? ¿Hay derechos a la buena imagen? Si lo es, ¿perjudicar la reputación de alguien diciendo x ha de ser delito? Si yo difamo se podría decir que estoy dañando el honor de alguien, pero es que el honor es algo intangible y sin existencia ontológica, por lo tanto, no estoy dañando nada físicamente. Pienso que no puede haber derechos en aquello que es intangible. Esto lo veo problemático

\footnotetext{
${ }^{26}$ Recomiendo dos libros sobre la cultura del victimismo en EEUU de Ben Shapiro, Bullies: How the left's culture of fear and intimidation silences americans (2010) y sobre el adoctrinamiento en las universidades Brainwhased: How universities indoctrinate America's youth (2014).

${ }^{27}$ Block defiende este tipo de planteamientos en libros como Defendiendo lo indefendible, Defendiendo la discriminación o Defendiendo el chantaje (2014; 2018; 2013).
} 
y peligroso que por el hecho de decir algo (esto no es otra cosa que por hablar) se me puede castigar judicialmente, es decir, pagar una multa o meterme en la cárcel x tiempo. Además, cuanto más se permite difamar, más difícil es difamar. Esto se puede ver con el ejemplo de Internet donde está permitido decir cualquier cosa sobre cualquier persona, pero como está permitido difamar y mentir nadie hace caso a nada de lo que la gente dice, en otras palabras, es más complicado difamar. Como todo el mundo miente aquel que quiera que la gente le haga caso ha de presentar una serie de pruebas, evidencia y justificaciones de que lo que dice es cierto, de que lo que dice lo dice en serio y ahí es cuando se le empieza a hacer caso, mientras tanto la gente pasa de él. Aquel que quiera que la gente le haga caso debe ganar previamente una reputación de persona seria y creíble. Lo que hace que se protejan cosas intangibles como el honor es que cualquiera pueda difamarlo sin prácticamente esfuerzo o prueba alguna como se ha hecho con personas como por ejemplo Woody Allen acusado fácilmente y sin pruebas de delitos sexuales de su pasado y difícilmente podrán borrar eso el resto de sus vidas. No protegiendo el honor es más difícil hacer daño a este pues pasaría como con Internet, nadie haría caso.

Es más, el honor, la buena imagen, la reputación son cosas que no pueden ser propiedad privada ni cosas de las que uno se pueda apropiar pues son representaciones de las demás personas sobre nosotros. La reputación de Spider-Man es la idea que tienen las personas sobre Spider-Man, algunos buena (como yo) y algunos mala (como John Jonah Jameson) y SpiderMan tendrá la reputación que tiene acorde con los pensamientos de otras personas. Querer apropiarse de la reputación y el honor de uno equivaldría entonces el querer apropiarse de los pensamientos de las demás personas. ¿Por qué esto no pasa con la bicicleta de Jaime? Primero, la bicicleta es tangible y tiene existencia ontológica, cosa que la reputación no. Segundo, la bicicleta es fácil de hacer propiedad privada, basta con ir a una tienda y hacer un intercambio libre y voluntario con el empleado de la tienda, tú le das dinero (cosa que el empleado valora) y él te da la bici (cosa que tú valoras). Con el honor esto no pasa, no he visto a gente nunca comerciar con las reputaciones y el honor, además el honor al ser intangible no es cuantificable, no puedes decir te doy +1 de honor o -1 de honor. Sólo se puede hacer esto en los videojuegos de rol, es decir, en mundos de fantasía y ficción. Tercero, puedes privar a los demás del uso de tu bici ya que es propiedad privada pero no puedes excluir a la gente de pensar lo que ellos crean conveniente sobre ti, ya que esto sería controlar sus cerebros y pensamientos y nadie quiere eso ya que las consecuencias serían desastrosas, el ejemplo lo tienen en 1984 de George Orwell (2013). El honor y la reputación no pueden ser propiedad privada de alguien ya que si fuera así invadiría otras libertades ajenas, como la de pensamiento o la de conciencia.

Claro está que la difamación puede perjudicar a las personas, por ejemplo, si se enteran de algún dato de mi vida pueden querer dejar de juntarse conmigo, pero yo no soy quién para decidir que dicen o dejan de decir de mí y que piensan o no piensan. Bien lo explica esto Daniel Duarte cuando dice que "el creer o no creer lo que dicen sobre mí es un acto voluntario y deliberativo exclusivo de cada individuo" (DUARTE, 2012). Si yo difamo mediante un medio de comunicación, el único que puede prohibírmelo es el propietario de ese medio, ya que es propiedad privada suya y él decide lo que se dice o no o lo que se publica o no en ese 
medio y no debería de decirlo una ley estatal como pasa con el caso del rey en España, donde difamarlo es delito.

Básicamente lo que quiero decir con esto es que la difamación debería ser despenalizada y que difamar es legítimo, otro debate sería si difamar es ético o no es ético. Yo pienso que difamar es legítimo, pero también prefiero una sociedad con gente educada que no difamase, pero esto es una preferencia mía que puede no ser realizable ya que yo no puedo controlar el comportamiento de las demás personas a no ser que sea con coerción y violencia, lo que sería ya ilegítimo. Por lo tanto, yo me limitaré a comportarme como yo crea conveniente y que queda uno haga lo que quiera y se comporte como quiera en libertad, es decir, siempre y cuando no dañe ni invada derechos y libertades ajenas.

Pero entonces, ¿dónde está el límite de la libertad de expresión? Desde mi punto de vista, estoy de acuerdo con Rothbard (2009) en que el límite estaría en la amenaza creíble de la propiedad de uno o de sus respectivas propiedades. La amenaza ha de ser creíble, palpable y directa. No lo sería entonces si yo le digo a mi amigo te voy a matar y luego voy a quemar tu casa pero sí lo sería si yo fuera un político y un extremista disidente me dijera eso mismo.

\section{Referencias}

ANDERSON, Benedict. Comunidades imaginadas. México: Fondo de cultura económica, 2006.

BACON, Francis. Nueva Atlántida. Madrid: Editorial Akal, 2006.

BENTHAM, Jeremy. An introduction to the principles of morals and legislation. CreateSpace Independent Publishing Platform, 2016.

BERLIN, Isaiah. Dos conceptos de libertad. El fin justifica los medios. Mi trayectoria intelectual. Madrid: Alianza editorial, 2014.

BLOCK, Walter. Defendiendo el chantaje. Londres: Editorial Innisfree, 2013.

BLOCK, Walter. Defendiendo la discriminación. Londres: Editorial Innisfree, 2018 [2016].

BLOCK, Walter. Defendiendo lo indefendible. Londres: Editorial Innisfree, 2014 [2012].

CARNEIRO, Robert. A theory of the origin of the State. Disponible en: https://science.sciencemag.org/ content/169/3947/733. Acceso en: 21 ago 1970.

CRAMB, Auslan. Anti-racism event hosted by Edinburgh University bans white people from asking questions. Disponible en: https://www.telegraph.co.uk/news/2019/09/27/anti-racism-event-hosted-edinburghuniversity-bans-white-people/. Acceso en: 27 sep 2019.

CONSTANT, Benjamin. Acerca de la libertad de los antiguos comparada a la de los modernos. Madrid: Alianza Editorial, 2019.

DE TOCQUEVILLE, Alexis. La democracia en América. Braga: Editorial Trotta, 2018.

DUARTE, Daniel. En defensa de la difamación. 2012. Disponible en: http://www.ordenvoluntario.com/172/ en-defensa-de-la-difamacion/. Acceso en: 31 jul 2012.

EDWARD KONKIN III, Samuel. Manifiesto neolibertario. Londres: Editorial Innisfree, 2011. 
ESPLUGAS BOTER, Albert. La comunicación en una sociedad libre: una crítica liberal al statu quo. Madrid: Instituto Juan de Mariana, 2008.

FLYNN, James. My Book Defending Free Speech Has Been Pulled. S/f. Disponible en: https://quillette. com/2019/09/24/my-book-defending-free-speech-has-been-banned/. Acceso en: 24 sep 2019.

GARCÍA GUITIÁN, Elena. Liberalismo y republicanismo: el uso político de los conceptos de libertad. 2008. Disponible en: http://rabida.uhu.es/dspace/bitstream/handle/10272/7074/Liberalismo_y_republicanismo. pdf?sequence=2. Acceso en: 1 oct 2008.

GODOY A., Óscar. Republicanismo, liberalismo y democracia. 2005. Disponible en: https://www.cepchile.cl/ cep/site/artic/20160304/asocfile/20160304093752/r99_godoy_republicanismo.pdf. Acceso en: 11 abril 2005.

HERMANN HOPPE, Hans. Democracia: el dios que fracasó. Buenos Aires: Unión editorial, 2013.

H. KNIGHT, Frank. Informe de lectura al director general y al Comité de Publicaciones de University of Chicago Press. Disponible en: file://C:/Users/Usuario/Desktop/camino-de-servidumbre-libro-electronico.pdf. Acceso en: 10 dec 1943.

HOBBES, Thomas, Leviatán. Ciudad del México: Fondo de Cultura Económica, 2018.

HUME, David. Ensayos políticos. Colombia: Editorial Anaya, 2006.

KAISER, Axel. La neoinquisición: Persecución, censura y decadencia cultural en el siglo XXI. Deusto: Editora Deusto, 2020.

KANT, Immanuel. Fundamentación para una metafísica de las costumbres. Madrid: Alianza editorial, 2012. KANT, Immanuel. Crítica de la razón práctica. Madrid: Alianza editorial, 2013.

L. ANDERSON, William. Speech: Free and Unfree. 2000. Disponible en: https://mises.org/library/speech-freeand-unfree. Acceso en: 2 ago 2000.

LÓPEZ JIMÉNEZ, José María. Dos conceptos de libertad y otros escritos. Disponible en: http://www.extoikos. es/n9/pdf/20.pdf. Acceso en: 2 ago 2013.

MANN, Michael. Las fuentes del poder social I y II. Madrid: Alianza Editorial, 1997 [1991].

MAYER, Christopher. Free Speech. 1999. Disponible en: https://mises.org/library/free-speech. Acceso en: 6 sep 1999.

MENGER, Carl. Principios de economía política. Buenos Aires: Unión Editorial, 1997.

NOZICK, Robert. Anarquía, Estado y utopía. Londres: Editorial Innisfree, 2014.

OPPENHEIMER, Franz. El Estado: su historia y evolución desde el punto de vista sociológico. Buenos Aires: Unión Editorial, 2014.

ORWELL, George. 1984. Madrid: Editorial DeBolsillo, 2013.

P. MALEK, Ninos. Free speech, free association and private property. 2003. Disponible en: https://mises.org/ library/free-speech-free-association-and-private-property. Acceso en: 5 jun 2003.

PAGLIA, Camille. Censurando a la maja desnuda. 2016. Disponible en: https:/ctxt.es/es/20160720/Culturas/7333/ libertad-de-expresi\%C3\%B3n-universidad-campus.htm. Acceso en: 20 jul 2016.

PETERSON, Jordan. Jordan Peterson swarmed by Narcissistic SJW Ideologues after UofT Rally. Disponible en: https://www.youtube.com/watch?v=O-nvNAcvUPE. Acceso en: 12 oct 2016.

PETTIT, Philippe. Republicanismo. Buenos Aires: Editorial Paidós, 1999. 
PINKER, Steven. En defensa de la Ilustración: por la razón, la ciencia, el humanismo y el progreso. Buenos Aires: Editorial Paidós, 2018.

PLATÓN. La República. Porto Alegre: Editorial Austral, 2011.

REEVES, V., Richard; HAIDT, Jonathan. John Stuart Mill ' s ideas on free speech illustrated. S/f. Disponible en: https://heterodoxacademy.org/mill/. Acesso en: 1 ene 2018.

REISMAN, George. Free speech and occupy Wall Street. 2011. Disponible en: https://mises.org/library/freespeech-and-occupy-wall-street. Acceso en: 21 dec 2011.

ROTHBARD, Murray. La Ética de la libertad. Buenos Aires: Unión editorial, 2009.

RUSTOW, Alexander. Freedom and domination. Princeton: Princeton University Press, 2014.

SHAPIRO, Ben. Brainwhased: How universities indoctrinate America's youth. Nashville: Thomas Nelson Publishers, 2010.

SHAPIRO, Ben. Bullies: How the left's culture of fear and intimidation silences americans. Nueva York: Treshold Editions, 2014.

SHAPIRO, Ben. Ben Shapiro at University of Wisconsin - Madison. Disponible en: https://www.youtube.com/ watch?v=bx11yxUe3Qc. Acceso en: 17 nov 2016.

SOWELL, Thomas. Conflicto de visions. Gedisa, 2013.

SPOONER, Lysandeer. Los vicios no son crímenes: una reivindicación de la libertad moral. 2012. Disponible en: http://www.mises.org.es/2012/08/los-vicios-no-son-delitos/http://www.sociales.uba.ar/wp-content/uploads/21Spooner.pdf. Acceso en: 17 ago 2018.

STUART MILL, John, Bentham: An essay on Jeremy Bentham. Strossmere Books, 2010.

STUART MILL, John. Capítulos para el socialismo. La civilización. Madrid: Alianza editorial, 2011.

STUART MILL, John. Consideraciones sobre el gobierno representativo. Madrid: Alianza editorial, 2001.

STUART MILL, John. El utilitarismo. Madrid: Alianza editorial, 2014.

STUART MILL, John. Sobre la libertad. Londres: Editorial Innisfree, 2019.

TERRELL, T. D. License tags and Free Speech. 2001. Disponible en: https://mises.org/library/license-tags-andfree-speech. Acceso en: 12 ene 2001.

TILLY, Charles. Guerra y construcción de estado como crimen organizado. 2007. Disponible en: https://revistas. uam.es/index.php/relacionesinternacionales/article/view/4866. Acceso en: 1 ene 2007.

VON HAYEK, Friedrich. Camino de servidumbre. Buenos Aires: Unión editorial, 2017.

VON MISES, Ludwig. La acción humana. Buenos Aires: Unión editorial, 2018.

VON MISES, Ludwig. Liberalismo. Buenos Aires: Unión editorial, 2011.

RECIBIDO: 12 DEC 2019.

APROBADO: 13 FEB 2020. 